\title{
Peculiarities of Erythrocytic Parameters in Patients with Nonalcoholic Steatohepatitis
}

\author{
Margarita V. Kruchinina ${ }^{*}$, Svetlana A. Kurilovich ${ }^{1}$, Andrey A. Gromov'1, \\ Vladimir M. Generalov², Vladimir N. Kruchinin ${ }^{3}$ \\ ${ }^{1}$ Federal State Budgetary of Scientific Institution "Institution of Internal and Preventive Medicine", \\ Novosibirsk, Russia \\ ${ }^{2}$ The State Research Center of Virology and Biotechnology VECTOR, \\ Koltsovo, Russia \\ ${ }^{3}$ Rzhanov Institute of Semiconductor Physics SB RAS, Novosibirsk, Russia \\ Email: *kruchmargo@yandex.ru
}

Received 19 February 2016; accepted 27 March 2016; published 30 March 2016

Copyright (C) 2016 by authors and Scientific Research Publishing Inc.

This work is licensed under the Creative Commons Attribution International License (CC BY). http://creativecommons.org/licenses/by/4.0/

(c) (i) Open Access

\section{Abstract}

Thirty-seven males with non-alcoholic staatohepatitis (NASH) (aged 39 - 62) were included in the study. Clinical, biochemical and instrumental studies were used to verify the diagnosis. The control group was comprised of thirty-three males of comparable age and without confirmed signs of liver diseases and other pathology of inner organs. Dielectrophoresis was applied to evaluate the structural-and-functional erythrocytic parameters. The patients with NASH erythrocytes tended to differ in their much lower amplitude deformation, polarizability, capacity of erythrocytic membranes, pace of translational motion of cells towards electrodes and much higher levels of overall indices of rigidity, viscosity, electroconductivity, destruction and aggregation as compared to the control group ( $p<0.001-0.05$ ). We discovered cases of correlation of erythrocytic parameters with biochemical findings reflecting inflammatory and cytolytic syndrome, cholestasis, proteinsynthesizing liver function as well as markers of metabolic syndrome (BMI, changes in arterial blood pressure, the degree of disturbances in carbohydrate metabolism, atherogenic dyslipidemia) and microalbuminuria. Aggravation of microcirculatory disturbances leading to an increase of fibrogenes is induced by changes in the properties of erythrocytes under NASH suggests the administration of a number of therapeutic techniques which could improve the status of the parameters of red blood cells. This study aims to evaluate the peculiarities of electric and viscoelastic behavior of erythrocytes in patients with primary NASH in order to determine additional methods of treatment for this disease.

*Corresponding author.

How to cite this paper: Kruchinina, M.V., Kurilovich, S.A., Gromov, A.A., Generalov, V.M. and Kruchinin, V.N. (2016) Peculiarities of Erythrocytic Parameters in Patients with Nonalcoholic Steatohepatitis. Journal of Analytical Sciences, Methods and Instrumentation, 6, 6-14. http://dx.doi.org/10.4236/jasmi.2016.61002 


\section{Keywords}

\section{Nonalcoholic Steatohepatitis, Electric, Viscoelastic Parameters, Erythrocytes, Dielectrophoresis}

\section{Introduction}

Nonalcoholic steatohepatitis (NASH) is a heterogenic group of pathologic changes in the liver characterized by inflammatory infiltration against a background of fatty degeneration of hepatocytes in individuals who do not consume alcohol in hepatotoxic dosages. The incidence rate of diagnosed NASH within the course of histological studies of the liver has recently increased and it comprises 7\% - 9\% both in Western Europe and in the USA [1]. The importance of early diagnosis and treatment of NASH is preconditioned by the following facts: an examination of large groups of patients with cryptogenic liver cirrhosis, including the evaluation of concomitant diseases and risk factors, led to the assumption that in $60 \%-80 \%$ of cases, liver cirrhosis of unclear etiology is based on undiagnosed NASH [1]. In the USA, $2 \%-6 \%$ of the total number of liver transplantations are known to be performed on NASH patients with decompensated liver cirrhosis [1]. Due to the fact that primary NASH, in the vast majority of cases, manifests itself as a metabolic syndrome, the growth of the latter signifies a steady increase in the number of NASH cases [1] [2]. Changes in erythrocytic parameters should be regarded as factors leading to the progression of NASH. Taking into account that erythrocytes are the most numerous blood cells and play an important role in maintaining homeostasis, changes in erythrocytic parameters in patients with metabolic syndrome are known to inevitably aggravate the course of NASH [1]. Correspondingly, therapeutic measures aimed to normalize such parameters of red blood cells as deformity, electroconductivity, capacity of membranes, etc. (along with treatment of manifestations of metabolic syndrome and removal of risk factors) that would obviously result in the minimization of manifestations of NASH.

This study aims to evaluate the peculiarities of electric and viscoelastic behavior of erythrocytes in patients with primary NASH in order to determine additional methods of treatment for this disease.

\section{Methods}

37 males with NASH (aged 39 - 62) were included in the study. A minimal activity rate of the process was registered in 11 subjects, and a moderate one in 26 . Laboratory signs of cytolysis were found in $43 \%$ of the patients with NASH; the level of serum transaminases did not exceed four normal values while the ALT/AST ratio was higher than one. Thirty-seven per cent of the patients demonstrated an increased activity rate of alkaline phosphatase (not more than twofold) and gamma-glutamyltranspeptidase. Hyperbilirubinemia (predominantly the mixed one) within a range of 1.5 - 2 times normal values was present in 23\% of the cases. Dysproteinemia of varying severity was found in $14 \%$ of the patients. In 8 patients, the presence of hypoalbuminemia was associated with the presence of diabetic nephropathy. Microalbuminuria (the excretion of 125 - $311 \mathrm{mg}$ of albumin in urine daily) was diagnosed in 22 patients in the study. Insignificant hypergammaglobulinemia (19\% - 22\%) was registered in $23 \%$ of the patients. The stage of the disease was evaluated on the basis of clinical, biochemical and instrumental studies. Ultrasound examination and computed tomography was used to verify the presence of hepatomegaly in all the patients in the study and indirectly evaluate the degree of liver fibrosis as moderate (2nd degree). Signs of the formation of hypertension were not present. Viral etiology of the disease was rejected due to the absence of serologic markers by applying the method of immune-enzymatic analysis (IEA) and/or DNA and RNA viruses by applying the method of polymerase chain reaction (PCR); the exclusion of alcoholrelated etiology was reliably confirmed by the absence of current or past systemic alcohol consumption registered in the case history of the patients (the regular and the CAGE-questionnaire were applied).

NASH in the patients of the study was regarded as a manifestation of metabolic syndrome. $48 \%$ of the patients were diagnosed with abdominal-and-visceral obesity with a BMI exceeding $30 \mathrm{~kg} / \mathrm{m}^{2}$. Arterial hypertension of degree I-II was registered in all the subjects under evaluation. Diabetes mellitus of Type 2 was confirmed in 12 males; the rest were found to have disturbances in glucose tolerance. Insulin-resistance was confirmed in all the patients in the study. In $12 \%$ of the cases, the level of glycosylated hemoglobin ranged between $4 \%$ and $6 \%$; in $64 \%$ of the cases-between $6.2 \%$ and $7.5 \%$, and in $24 \%$ of the patients it exceeded $7.5 \%$. Atherogenic dyslipidemia was registered in all the patients in the study, i.e. HLP of Type 2A and Type 2B was registered in 
$34 \%$ and in $76 \%$ of the cases, correspondingly. Twenty-one patients were diagnosed to have hyperuricemia. Erythrocytic parameters were studied simultaneously with the findings of biochemical blood analyses. Thirtythree practically healthy males aged 35 - 60 comprised the control group. They led a healthy lifestyle and consumed alcohol in moderate amounts 1 - 2 times a month. Clinical, laboratory and instrumental studies revealed no signs of liver pathology and other pathology of inner organs in them.

The study was carried out based on the approval of the Committee for Biomedical Ethics at the Federal State Budgetary Institution of Internal and Preventive Medicine, Siberian Branch under the Russian Academy of Medical Sciences. All the subjects in the study filled out the standard questionnaires, i.e. 1) Written consent from the patient for involvement in the study; 2) A standard questionnaire on the frequency and amount of alcohol consumed (to exclude potential hepatitis of alcoholic origin).

Both the patients with a verified diagnosis and the males in the control group underwent evaluation of electric and viscoelastic behavior of erythrocytes by means of dielectrophoresis (DEP) in non-uniform alternating electric field (NUAEF) generated by a special automated device [3]. Upon DEP, $2 \mathrm{ml}$ of blood was added to a 3.7\% citrate buffer in a ratio of 9:1; one hour later the blood was transported to a $0.3 \mathrm{M}$ saccharose (pH 7.36) solution in a ratio of 1:20. Right after cultivation, the erythrocytic parameters were evaluated. The blood cells in the measuring cell were treated with NUAEF of $10^{5} \mathrm{~V} / \mathrm{m}$, an electric field of gradient intensity of $10^{11} \mathrm{~V} / \mathrm{m}^{2}$ and a frequency range of $5 \times 10^{4}-10^{6} \mathrm{~Hz}$. The period of measurement and impact of NUAEF was 5 seconds.

The following were studied: the electroconductivity of membranes, the indices of aggregation and destruction of erythrocytes, the capacity of cellular erythrocytic membranes, the rate of movement of erythrocytes to electrodes, the location of crossover frequency, the amplitude of deformation of erythrocytes, cell polarizability on various frequences, summarized viscosity and rigidity, as well as values of induced dipole moment.

The dielectrophoresis-related data were treated statistically with application of the original CELLFIND software. Method replication error was equal to $7 \%-12 \%$. The rest of the data obtained were treated statistically using the SPSS, v.10 software. The Kholmogorov-Smirnov technique was used to define the nature of distribution of qualitative indicators. In cases of normal distribution the mean value $(\mathrm{M})$ and the standard error of the mean value $(\mathrm{m})$ were computed. The significance of the differences among the findings obtained was evaluated applying the Student's test. Pierson's test was applied in cases when distribution obeyed the regular law; in cases of deviations from the regular law the non-parametric criteria (U-criterion of Mann-Whitney, KholmogorovSmirnov) were applied. Correlations between the signs were evaluated based on computation of the Spearman's correlation coefficient (r). Within the whole course of the statistical treatment the critical level of significance of null hypothesis (p) was taken as 0.05 .

\section{Results and Discussion}

The control erythrocytes displayed a vivid ability to deform at a frequency of $0.5-1 \times 10^{6} \mathrm{~Hz}$ in NUAEF (Figure 1(a)).

They tended to gain high translational speed in the direction of the closest electrode and expand to the maximal degree demonstrating high pitches of deformation amplitude induced by NUAEF. In the majority of patients in the study, at a frequency range of $0.45-0.5 \times 10^{6} \mathrm{~Hz}$ axial rotation of erythrocytes was observed which corresponded to the crossover frequency rate. At a frequency of $0.05 \times 10^{6}$, and $0.1 \times 10^{6} \mathrm{~Hz}$, no deformation
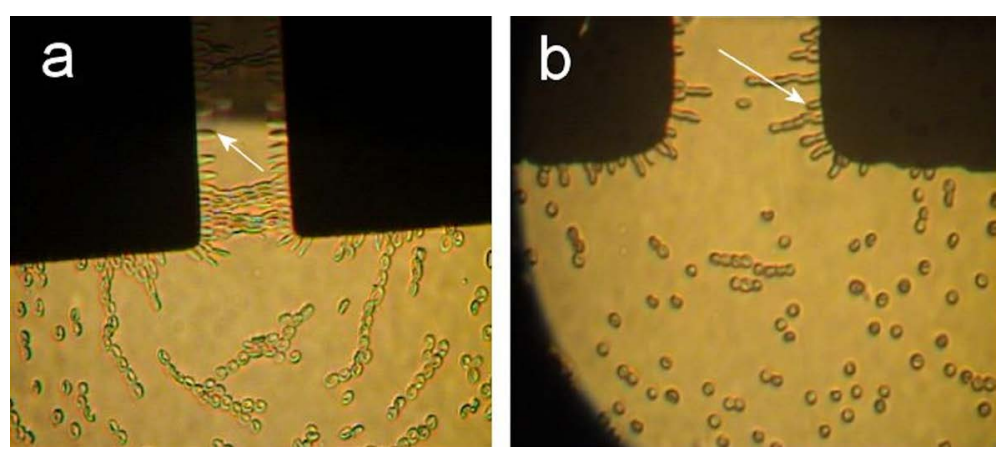

Figure 1. The division and deformation of erythrocytes at a frequency rate of $10^{6} \mathrm{~Hz}$ in the subjects: (a) the control group; (b) the patients with NASH. 
was registered; erythrocytes tended to push off the electrodes while sporadic cells were destroyed by the electric current. Studies of viscoelastic and electric erythrocytic parameters in patients with NASH demonstrated that red blood cells display a significantly lower amplitude of deformation. These facts were documented by video.

Figure 1(b) demonstrates significantly increased (as compared to the control group) summarized viscosity and rigidity, decreased superficial electric charge (displayed by a low pace of movement of erythrocytes towards electrodes), capacity of membranes, lability leading to increased hemolysis and, as a result, a tendency to form aggregates $(\mathrm{p}<0.001-0.05)$.

Decreased indices of polarizability at all frequencies in subjects with NASH in the study are specified in Table 1.

A significant decrease in cellular biological activity was registered against a background of increased tissue hypoxia, the latter being the factor provoking fibrogenesis [4] (see Table 2).

The crossover frequency in patients with nonalcoholic steatohepatitis shifted towards much higher frequencies (exceeding $5 \times 10^{5} \mathrm{~Hz}$ ). Increased indices of electroconductivity of erythrocyte membranes in patients with NASH reflected the ability of membranes to conduct electricity in a better way as compared to the control group where erythrocyte membranes acted as dielectrics. This fact indirectly speaks in favor of the presence of pronounced changes in the structure of erythrocyte membranes, in general, and changes in their lipid and phospholipid composition in patients with NASH, in particular.

Disturbance in the deformity of erythrocytes is known to occur in cases of changes in the lipid spectrum of

Table 1. Viscoelastic and electric erythrocytic parameters in patients with nonalcoholic steatohepatitis (NASH) and in the control group $(\mathrm{M} \pm \mathrm{m})$.

\begin{tabular}{|c|c|c|c|}
\hline \multirow[b]{2}{*}{ Erythrocytic parameters } & \multicolumn{3}{|c|}{ Study group } \\
\hline & $\begin{array}{c}\text { Control } \\
n=33\end{array}$ & $\begin{array}{l}\text { NASH } \\
n=37\end{array}$ & $\mathrm{P}<$ \\
\hline Amplitude of deformation, [m] & $2.6 \times 10^{-6} \pm 1.1 \times 10^{-7}$ & $0.62 \times 10^{-6} \pm 1.3 \times 10^{-7}$ & 0.0001 \\
\hline Summarized rigidity, $[\mathrm{H} / \mathrm{m}]$ & $4.2 \times 10^{-6} \pm 6.3 \times 10^{-7}$ & $8.12 \times 10^{-6} \pm 5.7 \times 10^{-6}$ & 0.001 \\
\hline Summarized viscosity, $[\mathrm{Pa} \cdot \mathrm{s}]$ & $0.32 \pm 0.05$ & $0.70 \pm 0.12$ & 0.01 \\
\hline Index of aggregation Er, [conventional units] & $0.42 \pm 0.011$ & $0.69 \pm 0.1$ & 0.01 \\
\hline Index of destruction $\mathrm{Er},[\%]$ & $1.09 \pm 0.72$ & $4.32 \pm 0.69$ & 0.002 \\
\hline Electroconductivity, [cm/m] & $2.91 \times 10^{-5} \pm 3.0 \times 10^{-6}$ & $6.51 \times 10^{-5} \pm 7.9 \times 10^{-6}$ & 0.001 \\
\hline Capacity of cellular membrane, [F] & $5.18 \times 10^{-14} \pm 2.23 \times 10^{-15}$ & $4.26 \times 10^{-14} \pm 2.97 \times 10^{-15}$ & 0.02 \\
\hline Pace of translation motion of Er to electrodes, $[\mu \mathrm{m} / \mathrm{s}]$ & $14.70 \pm 2.34$ & $8.12 \pm 2.11$ & 0.05 \\
\hline Crossover frequency, [Hz] & $4.65 \times 10^{5} \pm 4.63 \times 10^{6}$ & $6.21 \times 10^{5} \pm 4.57 \times 10^{6}$ & 0.02 \\
\hline Dipole moment, $[\mathrm{C} \cdot \mathrm{m}]$ & $1.42 \times 10^{-21} \pm 3.73 \times 10^{-22}$ & $5.84 \times 10^{-22} \pm 1.86 \times 10^{-22}$ & 0.05 \\
\hline
\end{tabular}

${ }^{\mathrm{a}}$ The value of the dipole moment was computed at a field strength of $8.85 \times 10^{-12} \mathrm{~F} / \mathrm{m}$.

Table 2. Polarizability of erythrocytes at different frequencies in patients with nonalcoholic steatohepatitis (NASH) and in the control group $(\mathrm{M} \pm \mathrm{m})$.

\begin{tabular}{|c|c|c|c|}
\hline \multirow[b]{2}{*}{ Erythrocytic polarizability, $\left[\mathrm{m}^{3}\right]$} & \multicolumn{3}{|c|}{ Study group } \\
\hline & $\begin{array}{c}\text { Control } \\
n=33\end{array}$ & $\begin{array}{c}\text { NASH } \\
n=37\end{array}$ & $\mathrm{P}<$ \\
\hline At $10^{6} \mathrm{~Hz}$ & $5.68 \times 10^{-15} \pm 7.1 \times 10^{-16}$ & $2.16 \times 10^{-15} \pm 9.4 \times 10^{-16}$ & 0.01 \\
\hline At $0.5 \times 10^{6} \mathrm{~Hz}$ & $1.6 \times 10^{-15} \pm 4.21 \times 10^{-16}$ & $0.66 \times 10^{-15} \pm 2.1 \times 10^{-16}$ & 0.05 \\
\hline At $0.1 \times 10^{6} \mathrm{~Hz}$ & $-1.0 \times 10^{-15} \pm 3.9 \times 10^{-16}$ & $-2.38 \times 10^{-15} \pm 2.8 \times 10^{-16}$ & 0.01 \\
\hline At $0.05 \times 10^{6} \mathrm{~Hz}$ & $-1.97 \times 10^{-15} \pm 2.21 \times 10^{-16}$ & $-3.25 \times 10^{-15} \pm 4.93 \times 10^{-16}$ & 0.02 \\
\hline
\end{tabular}


membranes. Primarily, it happens in the event of disturbance of the cholesterol/phospholipids ratio, as well as in the presence of products of membrane damage induced by lipid peroxidation (POL) [5]. POL products tend to induce a destabilizing effect on the structural-and-functional condition of erythrocytes and favor their modification. It can be observed in disturbances of physicochemical properties of erythrocyte membranes, both in qualitative and quantitative changes in membrane lipids, as well as in an increase of passive permeability of the lipid bilayer for $\mathrm{K}^{+}, \mathrm{H}^{+}, \mathrm{Ca}^{++}$. In recently published papers, the authors, having applied electron-spin resonance spectroscopy, registered a significant direct correlation between the aggravation of deformability of erythrocytes and markers of metabolic syndrome (body mass index (BMI), arterial blood pressure (ABP), glucose level following the glucose-tolerance test, atherogenic dyslipidemia) [1] [5]-[7] that is exemplarily confirmed by this study as well, i.e. the NASH-induced amplitude of deformity of erythrocytes inversely correlated with BMI $(r=-0.432$, $p<0.04)$, levels of ABP $(r=-0.511, p<0.05)$, glucose $(r=-0.394, p<0.03)$ and the presence of atherogenic dyslipidemia $(\mathrm{r}=-0.56, \mathrm{p}<0.02)$.

Deformity of erythrocytes also tended to decrease due to adsorption of plasma albumins on the surface of erythrocyte membranes [5]. It was primarily fibrinogen which reflected the severity rate of inflammation. In this study, the amplitude of erythrocyte deformity inversely correlated with the level of fibrinogen $(r=-0.402, p<$ 0.05). It comprised changes in membranes of erythrocytes, a decrease in the surface charge of erythrocytic membranes, changes in the shape of erythrocytes, as well as the ones on the part of plasma (i.e. changes in the concentration of albumins, the lipid spectrum, and the level of total cholesterol, fibrinogen, and heparin). A NASH-induced increased aggregation of erythrocytes tended to lead to disturbances in transcapillary metabolism, a discharge of biologically active substances (BAS), stimulation of adhesion and aggregation of thrombocytes, aggravation of microcirculatory disturbances in the liver, as well as fibrogenesis.

Evaluation of the polarization index within a broad frequency range makes it possible to selectively study the characteristics of the membrane and cellular cytoplasm or to integrally compare its properties to ambient electrolytes [8] [9]. Deacrease of the polarizability index at high and low frequency levels in patients with NASH (Table 2) speaks in favor of pronounced changes both in erythrocyte membranes, as well as in their inner content. Polarization illustrates a fine connection between the properties, composition and parameters of a cell on the microscopic level, and the properties, concentration and composition of its atoms and molecules. Changes in structure of erythrocyte membranes (its lipid and phospholipid component, in particular) can obviously be partially attributed to the effect of lipids in blood serum. However, some authors are of the opinion that the level of cholesterol, its esters in membranes of erythrocytes, does not depend upon the above-specified levels in blood serum [10]. NASH is known to be associated with hypertriglyceridemia more often than with hypercholesterolemia [1] [2]. In this study, cases of NASH demonstrated stronger correlations of the summarized viscosity $(\mathrm{r}=$ 0.721, $\mathrm{p}<0.014$ ) and deformation amplitude with the level of serum triglycerides as compared to the level of total cholesterol $(\mathrm{r}=0.312, \mathrm{p}<0.048, \mathrm{r}=0.402, \mathrm{p}<0.05$, correspondingly).

Leonova T. Ya et al. [11] proved erythrocytes to be capable of adsorbing of cholesterol-loaded blood plasma lipoproteins (in the form of very-low-density lipoproteins-VLDL, high-density lipoproteins-HDL and lowdensity lipoproteins-LDL) on their surface. This capability is defined based on the content of lipoproteins in the blood plasma and the cholesterol requirements of erythrocytes. Constant metabolism of cholesterol is known to take place among erythrocytes and lipoproteins adsorbed on their surface. The highest rate of cholesterol metabolism was registered between red blood cells and HDL; in this case blood serum lecithin-cholesterol-acyltransferase (LCAT) tended to play a significant role. Its synthesis takes place in the liver and to a significant degree is preconditioned by the condition of the organ. Hence, in cases of liver pathology, in general, and in cases of NASH, in particular, we observe a decreased level of LCAT [2] [12], consequently followed by an increased content of free cholesterol, initially in the blood serum and then in erythrocytes as well. This is due to the cholesterol-reducing capacity of erythrocytes which, on the one hand, tends to affect the intensity rate of the cholesterol metabolism between lipoproteins of serum and blood cells and, on the other hand, it keeps the content of cholesterol in erythrocytes within the physiological limits. Disturbances in this physiologically important mechanism of cholesterol metabolism regulation can result in hypercholesterolemia, which is one of manifestations of metabolic syndrome.

Accumulation of fat in the liver is known to be caused by the excessive transport of free fatty acids into the organ from the small intestine or fatty tissue, or due to active synthesis taking place directly in the hepatocytes. This process results in the excessive formation of VLDL by the hepatocytes. Blood analysis in patients with fatty liver disease is known to reveal pronounced hypertriglyceridemia, an increased level of cholesterol in VLDL, 
as well as a decrease in the concentration of cholesterol in HDL [2] [12]. One of the possible hypotheses explaining the contribution of erythrocytes to the progression of NASH deals with the involvement of red blood cells in the disturbed process of mutual lipid component metabolism taking place between the serum and tissues.

Both an increase and a decrease in the index of electric capacity of erythrocyte membranes in patients with NASH can signal changes in the thickness of the red blood cell membranes (Table 1). Various other factors most likely also contribute to the changes in this index in patients with NASH, including an increased metabolism with serum lipids confirmed by the reverse correlation between the capacity of erythrocyte membranes and the level of total cholesterol $(r=-0.321, p<0.05)$, and triglycerides $(r=-0.442, p<0.04)$. Additionally, there can be adsorption of the increased levels of fibrinogen $(r=-0.396, p<0.05)$. Finally, in the cases of NASH, changes in electric capacitance of erythrocyte membranes tended to correlate with the degree of dysproteinemia. Examples of the direct correlation of this index with the level of albumins $(r=0.428, p<0.05)$, and the indirect correlation with the level of gamma-globulins $(r=-0.501, p<0.03)$ have been registered as well.

Some authors [4] [13] confirmed that changes in the electric charge of erythrocytes tended to mainly depend upon the ratio of albumin fractions, i.e. the bigger the shift from the physiological condition, the smaller the decrease of the electric charge happened to be. A decrease in the electric charge of erythrocytes and an increase in the level of globulins in blood serum are believed to be connected to adsorption of globulin molecules on the surface of cells of globulin molecules as these molecules are known to have a much lower electric charge [13]. Many other researchers confirm the ability of globulins to adsorb on the surface of erythrocytes no matter their antigen structure. Dysproteinemia with an increased level of gamma-globulins was observed in cases of NASH [1] [12] [14]. It can be assumed that in patients with NASH, a decrease in the electric charge of erythrocytes, reflected by the reduced pace of shift towards electrodes, is preconditioned by changes in the ratio of albumin fractions.

In this study, the authors defined cases of correlation between a number of biochemical indices and the electric, viscoelastic properties of erythrocytes. The indices characteristic for cytolytic syndrome (an increase of the activity of ALT, AST as indicating enzymes) tended to be in direct, strong and highly significant correlation to the electroconductivity of erythrocyte membranes ( $r=0.711, p<0.03$ for ALT; $r=0.542, p<0.01$ for AST) and their polarizability ( $r=0.517, \mathrm{p}<0.02$ for ALT; $r=0.426$, $p<0.048$ for AST). Hyperbilirubinemia (because of the increased indirect fraction) tended to be directly connected to the levels of lysis of erythrocytes, i.e. the index of destruction $(r=0.716, p<0.02)$, and the index of aggregation of cells $(r=0.603, p<0.03)$. A significant increase in hemolysis of erythrocytes in patients with NASH $(\mathrm{p}<0.05)$, observed especially at high frequencies (a high-intensity stress "model"), most likely contributed to the increase in the level of indirect fraction of bilirubin that could result in the formation of concrements in the gallbladder. This phenomenon should be taken into account due to the risk of cholelithiasis formation in patients with NASH.

Biochemical manifestations of cholestatic syndrome (an increase in the activity rate of excretory enzymes of AP, GGTP) tended to reversely and significantly correlate with the electroconductivity of membranes $(r=$ $-0.396, \mathrm{p}<0.05$ for AP; $\mathrm{r}=-0.420, \mathrm{p}<0.03$ for GGTP) and their polarizability $(\mathrm{r}=-0.311, \mathrm{p}<0.048$ for AP; $\mathrm{r}=$ $-0.392, \mathrm{p}<0.05$ for GGTP).

A direct correlation of the severity rate of liver damage with the severity of disturbances in glucose metabolism was diagnosed $(r=0.571, \mathrm{p}<0.044)$. We also registered a direct and highly significant correlation between the level of glycosylated hemoglobin and the summarized rigidity $(r=0.724, p<0.01)$, as well as the reverse with the NUAEF-effected amplitude of the deformation of erythrocytes $(r=0.620, p<0.03)$. The degree of glycosylation of hemoglobin (i.e. non-enzymatic interaction with a formation of Schiff's bases) is known to depend on the concentration of the glucose level in the blood and the duration of the glucose's contact with hemoglobin, i.e. the degree of compensation of carbohydrate metabolism [15]. Conformational changes of glycosylated hemoglobin are known to serve as the markers of an increase in the "internal rigidity" of erythrocytes [16]. The lowering of the amplitude of deformation of red blood cells is known to result in a decrease of filling and, consequently, in desolation of the microcirculatory bed [17]. On the other hand, it is a well-known fact that the oxygen-transport function of erythrocytes depends not only on the quantity and properties of their hemoglobin but on the conditions of the functioning of the latter as well [18]. It was established that 2,3-DPG, along with the formation of specific complexes with hemoglobin, tends to significantly change the degree of affinity of hemoglobin to oxygen. Glycosylation of hemoglobin is known to impair the formation of complexes of the latter with 2,3-DPG that results in an increase in hypoxia due to the existence of this particular mechanism [16]. As it has been stressed before, hypoxia is known to be one of key factors of fibrogenesis [2] [4] [14] the degree of 
which defines the prognosis in cases of diffuse liver pathology, in general, and in cases of NASH, in particular.

The correlation between hypoxia and the development of NASH has been proven experimentally by A.-K. Pidget and her colleagues from Bern University (Switzerland). They kept experimental mice for a period of one week in an environment with a low oxygen content and discovered that such conditions caused an increase in the content of fats in the liver as well as inflammation; a biopsy concluded that steatohepatitis was present [19]. Besides, the mice kept under the low oxygen level conditions became less sensitive to insulin.

The development of insulin-independent diabetes mellitus is known to be closely associated with obesity [1]. Individuals with excessive body weight tend to have a lower sensitivity rate of their peripheral receptors to insulin in combination with a high level of insulin in the blood. Insulin is known to activate the synthesis of free fatty acids and triglycerides and decrease the rate of $\beta$-oxidation of free fatty acids in the liver and the secretion of lipids into the blood flow, which naturally results in deposits of fat in the liver. Insulin-resistance tends to affect the properties of erythrocytes due to the above mentioned fact that the C-peptide of pro-insulin happens to reduce deformation of cells and change their shape through exposure to the Na,K-ATPhase of erythrocyte membranes [20]. Thus, we are faced with a circulus vituosus which results in aggravation of the degree of tissue hypoxia.

Special emphasis should be given to the correlation revealed in this study of the index of microalbuminuria with the electric erythrocytic parameters; to be more precise, with the pace of translatory motion of erythrocytes towards electrodes $(r=0.72, p<0.033)$, with a value of dipole moment $(r=0.69, p<0.02)$, which reflects the density and value of the superficial negative charge of erythrocytes. A dipole characterizes spatial symmetry of distribution of electrical charges all over the whole volume of the cell. The vector of a dipole d moment, oriented from a positive charge to a negative one and depending on the charge and radius of the erythrocyte, served as a quantitative index of the dipole. Studies of microalbuminuria are traditionally applied in the screening of diabetic nephropathy. However, now the microalbuminuria test should be treated as an indicator of the evaluation of the function of plasma membranes of high-differentiated cells. Under normal conditions, the negatively charged albumin fails to get through the glomerular filter of the kidneys primarily due to the presence of a high negative charge on the surface of the epithelial cells. This charge is preconditioned by the structure of phospholipids of cellular membranes rich in polyunsaturated fatty acids. The decrease in the number of double bonds in acyl residua of phospholipids tends to decrease the negative charge and, as a result, increased amounts of albumin start being filtrated into the primary urine. All these changes tend to occur while atherosclerosis is developing. Therefore, microalbuminuria is likely to develop in cases of hereditary forms of hyperlipidemia, IHD, arterial hypertension, and in patients with disturbances in glucose tolerance. Changes in the structure of phospholipids of plasmodic membranes of high-differentiated cells (including erythrocytes, kidney cells, and hepatocytes) happen to occur in cases of atherosclerosis and immediately affect the charge of membranes. For this reason, it is easy to explain the close link between electric indices of erythrocytes and microalbuminuria, which serve as indicators of the early stages of the disease leading to NASH [15].

\section{Conclusions}

Thus, erythrocytes in patients with NASH tended to significantly differ in their lower deformation amplitude induced by NUAEF, polarizability, capacity of membranes, pace of shift of cells to electrodes and in the significantly higher levels of summarized rigidity, viscosity, electroconductivity, indices of destruction and aggregation as compared to the control group.

Correlations between electric and viscoelastic behavior of erythrocytes and biochemical findings reflecting inflammatory and cytolytic syndromes, cholestasis and albumin-synthesizing liver function were found in NASH patients in this study.

Connections between the index of deformity of erythrocytes and metabolic syndrome markers (BWI, degree of disturbances in carbohydrate metabolism, atherogenic dyslipidemia), and electric erythrocytic parameters and microalbuminuria, were determined as well.

Altered electric and viscoelastic erythrocytic parameters in patients with NASH serve as markers of an increase in microcirculatory disturbances, and as signs of tissue hypoxia resulting in an increase of fibrogenesis in the liver. Therefore, the treatment of NASH should include the administration of a complex of remedies aimed to improve the condition of the erythrocytic parameters as well as the instrumental control of the electric and viscoelastic properties of erythrocytes. 


\section{References}

[1] Ivashkin, V.T. and Lapinov, T.L. (2008) Gastroenterologiya. Natsionalnoyerukovodstvo (Gastroenterology. National Guide), Izd. Gruppa Geotar-Media, Moscow.

[2] Roitberg, G.Y. (2007) Metabolicheskiysindrom (Metabolic Syndrome). MEDpress-Inform, Moscow.

[3] Generalov, V.M., Bakirov, T.S., Pak, A.V., Zvolskiy, I.L., Zaitsev, B.N., Kruchinina, M.V., Kurilovich, S.A. and Sergeyev, A.N. (2008) Avtomatizirovannaya ustanovka izmereniya viazkouprugikh kharakteristik erytrotsitov ( (An Automated Device for Evaluation of Viscoelasticity of Erythrocytes). Naukoyemkiye Tekhnologiyi, 12, 28-33.

[4] Kruchinina, M.V., Kurilovich, S.A., Parulikova, M.V., Gromov, A.A., Bakirov, T.S., Generalov, V.M. and Pak, A.V. (2005) Viazkouprugiye i elektricheskiye kharakteristiki erytrotsitov pri razlichnoy stepeni fibroza pecheni (Viscoelastic and Electric Properties of Erythrocytes in Various Degree of Liver Fibrosis).Vestnik NGU, 3, 43-52.

[5] Katiukhin, L.N. (1995) Reologicheskiye svoistva erytrotsitov. Sovremenniye metody issledovaniya (Rheological Properties of Erythrocytes. Modern methods of Study). Rossiyskiy fiziologicheskiy zhurnal im. I.M. Sechenova, 81, 122-129.

[6] Shylov, A.M. and Melnik, M.V. (2005) Arterialnaya gipertoniya i reologicheskiye svoistva krovi (Arterial Hypertension and Rheological Properties of Blood). BARS, Moscow.

[7] Banerjee, R., Nageshwari, K. and Puniyani, R.R. (1988) The Diagnostic Relevance of Red Cell Rigidity. Clinical Hemorheology and Microcirculation, 19, 21-24.

[8] Markx, G.H., Penelope, A.D. and Pethig, R. (1996) Dielectrophoretic Separation of Bacteria Using a Conductivity Gradient. Journal of Biotechnology, 51, 175-180. http://dx.doi.org/10.1016/0168-1656(96)01617-3

[9] Bakirov, T.S., Generalov, V.M., Durymanov, A.G., Poryvayev, V.D. and Toporkov, V.S. (2000) Ekvivalentnaya elektricheskaya skhema kletki (Equivalent Electrical Pattern of a Cell). Biotekhnologiya, 2, 53-59.

[10] Tziakas, D.N., Kaski, J.C., Chalikias, G.K., Romero, C., Fredericks, S., Tentes, I.K., Kortsaris, A.X., Hatseras, D.I. and Holt, D.W. (2007) Total Cholesterol Content of Erythrocyte Membranes Is Increased in Patients with Acute Coronary Syndrome. A New Marker of Clinical Instability? Journal of the American College of Cardiology, 49, 2081-2089. http://dx.doi.org/10.1016/j.jacc.2006.08.069

[11] Leonova, T.Y. (1982) K voprosu ob erytrotsitarnom mekhanizme regulirovaniya kholesterinemii pri eksperimentalnoy giperkholisterinemii i ishemicheskoy bolezni serdtsa (On the Issue of Erythrocytic Mechanism of Regulation of Cholesterolemia in Experimental Hypercholesterolemia and Ischemic Heart Disease). Ph.D., Novosibirsk.

[12] Ivashkin, V.T., Drapkina, O.M., Pavlov, Ch.S, Bakulin, I.G. and Korneyeva, O.N. (2007) Nealkogolniy steatogepatit pri metabolicheskom Syndrome (Nonalcoholic Steatohepatitis in Metabolic Syndrome). Consilium Medicum. Gastroenterologiya, 2, 18-21.

[13] Kozinets, G.I. and Makarov, V.A. (1997) Issledovaniye sistemy krovi v klinicheskoy praktike (Studies of Blood System in Clinical Practice). Triada-X, Moscow.

[14] Podymova, S.D. (1993) Boleznipecheni (Liver Diseases). Meditsina, Moscow.

[15] Kishkun, A.A. (2007) Rukovodstvo po laboratornym metodam diagnistiki (Manual on Laboratory Methods of Diagnosis). GEOTAR-Media, Moscow.

[16] Shilov, A.M., Avshalumov, A.Sh., Sinitsina, Ye.N., Markovskiy, V.B. and Poleshchuk, O.I. (2008) Izmeneniya reologicheskikh svoistv krovi u bolnykh s metabolicheskim sindromom (Changes in Rheological Properties of Blood in Patients with Metabolic Syndrome). Russkiy Meditsinskiy Zhurnal, 16, 200-204.

[17] Feihl, F., Liauder, L., Waeber, B. and Levy, B.I. (2006) Hypertension-A Disease of the Microcirculation? Hypertension, 48, 1012-1017. http://dx.doi.org/10.1161/01.HYP.0000249510.20326.72

[18] Novitskiy, V.V., Riazantseva, N.V. and Stepovaya, Ye.A. (2004) Fiziologiya i patofiziologiya erytrotcita (Physiology and Pathophysiology of Erythrocytes). Izdatelstvovo TGU, Tomsk.

[19] Piguet, A.Ch., Stroka, D., Zimmermann, A. and Dufour, J.F. (2010) Hypoxia Aggravates Non-Alcoholic Steatohepatitis in Mice lacking Hepatocellular PTEN. Clinical Science, 118, 401-410. http://dx.doi.org/10.1042/CS20090313

[20] Haffner, S.M., Gingerick, R., Stern, M.P., Bowsher, R.R. and Miettinen, H. (1995) Principal Proinsulin and Specific Insulin Are Associated with the Source of Diabetes among the Mexicans, Not Diabetes. Journal of Diabetes, 44, 11561160. http://dx.doi.org/10.2337/diab.44.10.1156 


\section{List of Abbreviations Used}

$\begin{array}{ll}\text { ABP } & \text {-arterial blood pressure } \\ \text { ALT } & \text {-alanine aminotransferase } \\ \text { AP } & \text {-alkaline phosphatase } \\ \text { AST } & \text {-aspartate aminotransferase } \\ \text { BAS } & \text {-biologically active substances } \\ \text { BMI } & \text {-body mass index } \\ \text { DEP } & \text {-dielectrophoresis } \\ \text { DNA } & \text {-deoxyribonucleic acid } \\ \text { GGTP } & \text {-gamma-glutamyltranspeptidase } \\ \text { HDL } & \text {-high-density lipoproteins } \\ \text { HLP } & \text {-hyperlipoproteinemia } \\ \text { IEA } & \text {-immune-enzymatic analysis } \\ \text { LCAT } & \text {-lecithin-cholesterol-acyltransferase } \\ \text { LDL } & \text {-Low density lipoprotein } \\ \text { Na,K } & \text {-ATPhase-sodium-potassium adenosine triphosphatase } \\ \text { NASH } & \text {-nonalcoholic steatohepatitis } \\ \text { NUAEF } & \text {-non-uniform alternating electric field } \\ \text { PCR } & \text {-polymerase chain reaction } \\ \text { RNA } & \text {-ribonucleic acid } \\ \text { POL } & \text {-lipid peroxidation } \\ \text { 2,3-DPG } & \text {-2,3-diphosphoglycerate } \\ \text { VLDL } & \text {-very-low-density lipoprotein }\end{array}$

